\title{
Coherence through Katherine Mansfield's Miss Brill
}

\author{
Dunya Muhamed Miqdad ${ }^{1}$ \\ ${ }^{1}$ Department of English Language, College of Education for Human Sciences, University of Babylon, Babylon, \\ Iraq \\ Correspondence: Dunya Muhamed Miqdad, Department of English Language, College of Education for Human \\ Sciences, University of Babylon, Babylon, Iraq. E-mail: dunya.ijam@yahoo.com
}

Received: April 4, 2014 Accepted: June 4, 2014 Online Published: July 29, 2014

doi: 10.5539/ijel.v4n4p44

URL: http://dx.doi.org/10.5539/ijel.v4n4p44

\begin{abstract}
This study includes an analysis of coherence to one of the famous short stories of Katherine Mansfield "Miss Brill". The paper tries to define coherence and what to follow in order to understand how a text is coherent. In fact, it is not a condition that a cohesive text must be coherent and vice versa. Each relation is found and possible to be analyzed according to different models and to totally different criteria. Therefore, the researcher attempts to analyze the short story according to a mixed model: that of Van Dijk and that of Winter.
\end{abstract}

Keywords: coherence, coherence relations, global coherence, local coherence, Miss Brill

\section{Introduction}

In discourse studies, coherence is often described as the way in which a discourse is "sewn" together with pieces related to other pieces. Mann and Thompson (1988, cited in Renkema, 2009) defined it as the absence of non-sequitures, i.e., a coherent. Text is one where all the parts form the whole: for every paragraph included in any discourse has a benefit of connecting the events and consequences to the previous and the next paragraph keeping the whole discourse coherent to the reader. Renkema (2004, p. 103, cited in Renkema, 2009) indicates that coherence refers to the inferences made by the receiver (reader/listener) depending upon his understanding the text and relating it to the outside world. Those connections are often captured in the form of coherence relations.

Al-Sahlany (2013) states that the basic conditions of coherence are referential (extensional) and not based on conceptual (intentional). He defines discourse coherence as a "sequence of propositions is coherent if the facts, events, actions and situations it refers to, are related". This relation may be casual, temporal, or enabling. In other words, a discourse is coherent if it satisfies a model and the relations between facts denoted by the propositions and the participants need an amount of the world knowledge. More shared knowledge allows discourse to be more "incomplete" or "less explicit". The definition of discourse coherence emphasizes that different mental models of a text knowledge, emotional involvement and goals as contextual properties of participants may influence the way they construe, more or less mental models of the texts by readers (their models) may be very different from that intended by the writer.

The idea of language function can go a long way towards solving the problem of what binds utterances together as a discourse in the absence of formal links. If we can ascertain the function of utterances, we will be able to perceive a unity of a different kind. Coherence for (Cook, 1989) is the quality of meaning, unity, and purpose perceived in discourse. Blommaert (2005) asserts that coherence is those grammatical and semantic patterns that connect various parts of discourse into a structural and meaningful whole.

In studying coherence, at paragraphs of any discourse which include units of meaning of varying complexity, the cognitive perspective becomes more important. These semantic units of their connection to the receiver's understanding is to have a coherent discourse, and according to the reader's inference activity, this connection may be either explicit on the surface or completely untrusted. Thus, this relation between successive individual units (words or sentences) is called local coherence, while logic that defines the place of individual units in the hierarchy themes and subthemes is called global coherence. 


\section{Kind of Coherence}

\subsection{Local Coherence}

A discourse is locally coherent if the meaning of the sentences is related in some way. Al-Sahlany (2013) argues that local coherence may be referential or functional. A discourse sequence is referentially coherent if it has a model. Functional local coherence is defined in terms of the relations between the propositions themselves. For example, where one proposition has the function of being a specification, a generalization, an example or contrast of another proposition.

Accordingly, local coherence is defined as a way of connecting successive sentences and paragraphs coherently by the aids of the successive relatedness of the ideas connecting the sentences and paragraphs together. Local coherence is achieved by the reciever's (reader's/listener's) following the theme development of the discourse and making it coherent depending upon the writer's help through providing lexical clues and using suitable style to make the discourse coherent.

Van Dijik and Kintsch (1983, pp. 10-13, cited in Beaugrande, 1991) assert that local coherence strategies work from bottom-up with words and phrases to top-down with a schema, frame or macro propositions.

\subsection{Global Coherence}

It is a collective contextual framework at the level of whole text. While Al-Sahlany (2013) views global coherence of any discourse is reflected through how it is arranged, developed, and related. Concerning this issue, Beaugrande (1991) defines global coherence as top-down states macrostates coming from outside the text about what is going on in the textual world. However, Van Dijik and Kintsch (1983, p. 106, cited in Beaugrande, 1991) identified global coherence as the collective meaning of fragments of discourse strategies as top-down data and it imposes unity and sequence on a text.

Cohesion alone does not necessarily result in coherence, as in:

It is quite cold out today. Consequently; I do not plan to wear a warm jacket.

The second sequence in the example above contains a marker of cohesion - consequently - that indicates that the second sentence is a logical consequence of the first. However, this short sequence is not coherent because the second sentence is actually not a logical consequence of the first: the second sentence would be logically more sound if the speaker has said that he planned to wear a warm jacket. What this example illustrates is that cohesion does not necessarily produce coherence, unless the cohesive link is used to mark a relation that already exists in the text. As a result, cohesion is in contrast with coherence concerns the general level, how more than one sentence found in a discourse are connected delibratly.

To sum up, Renkema (2009) emphasizes that a coherent text is recognized by the global meaning that readers can make of it. To help the reader make sense of a text, authors link new and old information within sentences and paragraphs, i.e., they build the textual coherence at micro-and macro levels as they go through the writing process.

\section{Top-Down and Bottom-Up Processing}

To understand a text happens by means of computational modeling of language understanding. The processing of a discourse is a two stage activity:

In the first stage, there is a working out of the meaning of words and structures of a sentence and build up a composite meaning for the sentence (i.e., bottom-up processing). At the same time, there is predicting, on the basis of the context plus the composite meaning of sentences already processed, what the next sentence is most likely to mean (i.e., top-down) (ibid).

\section{The Model}

According to (Van Dijk, 1980), "coherence relations" are found among discourse paragraphs and the suggested model might be suitable to be assigned to them. However, "all the babies" means the babies that are mentioned backward in the same discourse only. He adds that "a discourse is some contrasted propositions without being inconsistent". What is important is the homogeneity in a certain range, i.e., "the set of possible individuals or individual concepts to which they can be assigned or applied", as in:

The boy is ill.

is meaningful if the individual indicated actualize an individual concept "boy" belonging to the range of the property "ill". However, the properties assigned to the same individual must have overlapping ranges, otherwise they could not apply to the same individual. Thus, the ranges of "following" and "walking" do not overlap such 
that "boy" belongs to the intersection. Yet "having red hair" and "being ill" may have overlapping ranges, although these properties are not as such directly related. These properties belong to different dimensions (of physical appearance or having colour and health respectively). For him a dimension is a "basic category defining sets of properties". Individuals maybe compared with respect to a certain dimension and thus be more or less (dis)similar.

It is important to shed lights on how the range, dimension, comparability, and similarity of meaning are involved in the definition of discourse coherence.

Van Dijk (ibid) raises some questions about what are the conditions that make a passage coherent. He answered them by first mentioning the "individual identity in the model sequence". Through this identity; he includes relations as inclusions, membership, part-whole, and possession.

The inclusion of individuals with concepts and "a set of individuals thus related by identity or partiality through successive models is called series". He mentions other kind of coherence relations which is the predicate relations which they need only exist between predicates assigned to the same individual(s) of one series. This is so because, for instance, the predicates are related since they denote a possible sequence of activities, bodily states and mental (emotional) states for the human series. In addition, he offers time/period and place identity associated with the activity sequence and other series. (ibid)

Later on, he sheds lights on the semantic coherence in the assumed normality of the worlds involved. In other words, the receiver's predictions concerning the unified meaning of the text depend upon his awareness about the structures of worlds in general and of particular states of affairs or courses of events. Such kind of set is called frame which includes typical individuals and typical activities in that frame. The frames include paragraphs filled with sentences with the expected orderings of facts as the cause-consequence and general - particular or whole - part.

In spite of that, "the words and the world" relation is sometimes indirect. This is so because the text may include a small amount of facts of some situations and in some situations there will be redundancy in mentioning them. What is more is the verity in the ordering of facts because of pragmatic and cognitive reasons.

Elsewhere, he says that facts are not often linearly ordered but spatially and herarichally; for example, the ordering of discourse is called "normal" if the action, referred to, occurs as a part of the respective clauses, for example: $<$ beforeSj, $\mathrm{Si}>$ or $<\mathrm{SJ}$ afterSi $>$ where before $\mathrm{SJ}$ and after $\mathrm{Si}$ are subordinate to $\mathrm{Si}$ and $\mathrm{Sj}$ respectively.

He proposes a substitution to the normal "ordering" which is a shift in situation (world-time-place) by suitable parts of speech. Verbs as "think, believe, and remember, etc." followed by past tenses or adverbs as "yesterday" or adjectives as "previous" to give access to past time models with respect to actual-time models. Sometimes, there is no changed representations of order of the facts because the past events are embedded in the present.

Normal ordering is achieved by means of time connection between events by condition-sequence ordering of events, i.e., the consequences of events are developed from the start mentioning of events up to the climax then to the final events according to the temporal relatedness between them. To sum up, he introduces some types of ordering dependent relations as:

General-particular

Whole-particular

Set-subset/element

Large-small

Outside-inside

Possessor-possessed. (ibid)

Previously, Winter (1971) proposed a model to describe some semantic clause relations that help to build the coherence of the text. In his work, he distinguished between outer clause relations (connection between sentences) and inner clause relations (connected by subordination) in scientific and non-scientific material. He also presented his first definition of clause relation: "a clause relation is the way in which the information of one clause is understood in the light of the other clause" (Ibid). In 1977, Winter defines clause relations as a "system of predictability of context, that is, given one sentence within its preceding contexts the lexical selection of the next sentence is frequently predictable". He offered three kinds of lexical relations and it is clear in the following examples:

1) By-appealing to scientists and technologists to support his party, Mrs. Wilson won many middle class votes in 
the election.

2) He thereby won many middle class votes in the election.

3) Mrs. Wilson's appeals to scientists and technologists to support his party were instructed in winning many middle class votes in the election.

Winter introduced some kinds of relations, as:

1) Simple Comparison

2) Simple Contrast

3) Alternation Relation

4) Cause-Consequence

5) Condition-Consequence

6) Instrument-Acheivement

7) Generalaization-Example

8) Statement-Exception

9) Term-Specification

10) General-Particular

The researcher makes use of both models to analyze the data.

\title{
5. Data Analysis
}

\subsection{Local Coherence}

In the first paragraph:

\begin{abstract}
Although it was so brilliantly fine-the blue sky powdered with gold and great spots of light like white wine splashed over the Jardins Publiques—Miss Brill was glad that she had decided on her fur. The air was motionless, but when you opened your mouth there was just a faint chill, like a chill from a glass of iced water before you sip, and now and again a leaf came drifting-from nowhere, from the sky. Miss Brill put up her hand and touched her fur. Dear little thing! It was nice to feel it again. She had taken it out of its box that afternoon, shaken out the moth-powder, given it a good brush, and rubbed the life back into the dim little eyes. "What has been happening to me?" said the sad little eyes. Oh, how sweet it was to see them snap at her again from the red eiderdown! ... But the nose, which was of some black composition, wasn't at all firm. It must have had a knock, somehow. Never mind-a little dab of black sealing-wax when the time came - when it was absolutely necessary. ... Little rogue! Yes, she really felt like that about it. Little rogue biting its tail just by her left ear. She could have taken it off and laid it on her lap and stroked it. She felt a tingling in her hands and arms, but that came from walking, she supposed. And when she breathed, something light and sad-no, not sad, exactly-something gentle seemed to move in her bosom. (Mansfield, 1981)
\end{abstract}

The first two sentences show the location where most of the story holds according to the place identity in the model sequence. The park is identified through: blue sky, spots of light, air, a faint chill, and a leaf. The relations, here, are those of inclusion and whole-part, i.e., the park is part of the city, spots of light is included in the weather in the park scene, the air is part of the place, the leaf is part of the tree, etc.

Another kind of identity is the individual identity: Miss Brill and other individuals like fur, her hands, little thing, out of its box, little rogue, her hands and arms. Another kind of identity is symbolized in the fur, so, there is the identity of the box, moth-powder, good brush, the nose, etc. In fact, the fur and Miss Brill refer to the same identity. The writer made an indirect representation to the sameness case of the fur and Miss Brill by indicating that Miss Brill is just like her fur as having dim little eyes and nose as well as the activity sequences performed by her just to show the identical state of Miss Brill and her fur.

In general, the individuals are about the human (female) concept and the park concept. A set of individuals are related by identity or partiality through the series. Such kind of series are related by the predicate relations as the state of the sky, the motionless air, opening her month, there was just a faint chill, a leaf coming from the sky and putting the hand and touching her fur, feeling it, taking it out of its box, giving it off, laying it on her lap, breathing, move in her bosom, etc.

In addition to those activity sequences, the paragraph is coherent due to time/period place identity and the 
park-Miss Brill series.

There is semantic clue of coherence found here, it is the assumed normality of the worlds involved. In other words, the predicted semantic structures of text are determined by the reader's knowledge about the worlds in general and particular. Therefore, the activities indicated and the course of events and the states are found within a normal frame (the park frame). In the second paragraph:

There were a number of people out this afternoon, far more than last Sunday. And the band sounded louder and gayer. That was because the Season had begun. For although the band played all the year round on Sundays, out of season it was never the same. It was like someone playing with only the family to listen; it didn't care how it played if there weren't any strangers present. Wasn't the conductor wearing a new coat, too? She was sure it was new. He scraped with his foot and flapped his arms like a rooster about to crow, and the bandsmen sitting in the green rotunda blew out their cheeks and glared at the music. Now there came a little "flutey" bit-very pretty! - a little chain of bright drops. She was sure it would be repeated. It was; she lifted her head and smiled. (Mansfield, 1981)

The first sentence is directly coherent with the first paragraph because of the inclusion relation and time identity in the park frame. This is so because people usually go to the park as Miss Brill did. The identity of the time refers to the time at which the whole story holds. The last word of the first sentence "this afternoon" is related to "last Sunday" in the second sentence by a comparison relation and a part-whole relation, i.e., part of this Sunday (afternoon) is compared with the same part but of the last Sunday (its) afternoon.

Inclusion relation is also indicated through the band that is included in the park frame. This band performs a predicate relation by "sounded louder and grayer". The cause relation indicated and related to the band is that of their performance was because of the beginning of the season. The season here is capitalized. This is an abnormal use of capitalization. But this abnormality is necessary to make the reader understand that the season is of the time identity of the activity sequence and the park-Miss Brill series.

Then there is an identification of sameness relation indicating the beautiful playing of the band just like a person playing among his family. A set-subset-element relation is clear by producing a question indicating that the conductor is a member of the band and the new coat she is wondering about is part of the conductor's possessions.

The scene is now identified through Miss Brill's eyes as if they were a camera eye by describing the activities done by "the conductor" that is referred to by "he" having the same identity and parts of him is his arms about to do an activity similar to that of a roaster's which is to crow. The third paragraph,

Only two people shared her "special" seat: a fine old man in a velvet coat, his hands clasped over a huge carved walking-stick, and a big old woman, sitting upright, with a roll of knitting on her embroidered apron. They did not speak. This was disappointing, for Miss Brill always looked forward to the conversation. She had become really quite expert, she thought, at listening as though she didn't listen, at sitting in other people's lives just for a minute while they talked round her. (Mansfield, 1981)

starts with a coherence link with the two previous paragraphs through a part/whole relation, i.e., through Miss Brill and her "special seat" which is shared by "only two people". There is a set/subset/element relation. The second two sentences are employed to describe the people identity which is part of the park series. Therefore, those two sentences are coherent. Another relation is revealed through possessor/possessed relation with identities as: old man, old woman, in a velvet coat, his hands, a huge curved walking-stick, upright, with a roll of knitting on her embroidered apron. There are also predicate relations described by: clasped, sitting, and did not speak.

One of the habits Miss Brill was always doing is listening to conversation. This is described through a link between the previous activity done by the couple. This is a cause and sequence relation: since they did not speak, Miss Brill was disappointed. through the last sentence, there is an activity sequence done by Miss Brill as being "expert", "listening as though she did not listen and" sitting". The word "sitting" is coherently used from the first paragraph describing the state of Miss Brill by spending her time sitting in the park to "sit" in other people's lives when they talked around her. Therefore, there is a link between the components of the park-Miss Brill's series through: Miss Brill, the park, the seat, people around, the band, etc.

The fourth paragraph,

She glanced, sideways, at the old couple. Perhaps they would go soon. Last Sunday, too, hadn't been as interesting as usual. An Englishman and his wife, he wearing a dreadful Panama hat and she button boots. And she'd gone on the whole time about how she ought to wear spectacles; she knew she needed 
them; but that it was no good getting any; they'd be sure to break and they'd never keep on. And he'd been so patient. He'd suggested everything-gold rims, the kind that curved round your ears, little pads inside the bridge. No, nothing would please her. "They'll always be sliding down my nose!" Miss Brill had wanted to shake her. (Mansfield, 1981)

is linked through the first sentence of Miss Brill's activity sequence in the park- Miss Brill frame. Through "glanced" and the presupposition that "they would go". "They" is referred back to the "two people" mentioned in the third paragraph who are found in the same park-frame.

The sentence: "Last Sunday, too, had not been interesting as usual" is coherent since it shows a past thought or recall a world that is the past of the actual world. It is coherent because it is related to the "present actual world of the agent" (Dijk, 1980). This is clear through the sameness comparison relation between this Sunday and the last one by both not being "as interesting as usual".

A normal coherence shift is established through another couple: "an English man and his wife". Through the camera eye of Miss Brill, there was a full description of part of the park frame through the identities of a possessor/possessed relation: he: wearing a dreadful Panama hat, she: button boots, and spectacles. A general/particular relation is found through the description of activity sequence of: needing them (spectacles), it was no good getting any, they'd be sure to break, suggesting gold rims, the kind that curved your ears, little pads inside the bridge. Dissatisfaction of the suggestion, by the wife, is clear through introducing "they'll always be sliding down my nose". So part of the park frame is people lives frame. This is clear through not only picturing other people's conversations and descriptions but even through Miss Brill's wishes to interfere by a predicate relation: "Miss Brill had wanted to shake her". "Her" is an identity of the woman. The fifth paragraph,

The old people sat on the bench, still as statues. Never mind, there was always the crowd to watch. To and fro, in front of the flower-beds and the band rotunda, the couples and groups paraded, stopped to talk, to greet, to buy a handful of flowers from the old beggar who had his tray fixed to the railings. Little children ran among them, swooping and laughing; little boys with big white silk bows under their chins, little girls, little French dolls, dressed up in velvet and lace. And sometimes a tiny staggerer came suddenly rocking into the open from under the trees, stopped, stared, as suddenly sat down "flop," until its small high-stepping mother, like a young hen, rushed scolding to its rescue. Other people sat on the benches and green chairs, but they were nearly always the same, Sunday after Sunday, and-Miss Brill had often noticed - there was something funny about nearly all of them. They were odd, silent, nearly all old, and from the way they stared they looked as though they'd just come from dark little rooms or even-even cupboards! (Mansfield, 1981)

also perfectly linked with the previous one by an identity relation described by "the old people" referring to the same "couple" found in the previous paragraph. The camera eye of Miss Brill is now switched from watching the old people because they sat on the bench (a part of the park frame), to see other parts of the park series. Stick to the frame, there is a place relation introduced to the scene to deepen the sense that Miss Brill is watching carefully the place identity and the people's identity.

By identifying a location "in front of the flower beds and the band rotunda", there were many predicate relations describing many activity sequences, as: "paraded, stopped to talk, to greet, to buy", children "run down, rushed, sat on the benches". All these relations are introduced to indicate the activities performed by different people around Miss Brill at the park while she was watching. A new identity is introduced to the scene, but still within the park frame, "the old beggar", it is coherent since it is related to the park frame by the predicate relation through the couples and groups identity by buying " $a$ handful of flowers from the old beggar". In addition, there was a full description of the people identity of the children, little girls, little French dolls, etc.

In fact, Miss Brill came up with a conclusion and this conclusion is clearly represented her case. This conclusion resembles a sameness relation by describing the people, who came to the park. "Sunday after Sunday, as being old, nearly all old, and from the way they stared they looked as though they'd just come from dark little rooms or even-even cupboards".

The reference of little rooms is coherently related to the same little room of Miss Brill mentioned in the first paragraph. What is more, mentioning the "cupboard" from where Miss Brill's fur was found which is used by the writer to represent Miss Brill's state. Therefore, the "cupboard" here is coherently related to the "cupboard" introduced in the first paragraph to indicate that all the people found in the park are similar to Miss Brill (or even her fur) in being old, odd, and coming from dark little rooms or even cupboards.

The reference of little rooms is coherently related to the same little room of Miss Brill mentioned in the first 
paragraph. What is more, mentioning the "cupboard" from where Miss Brill's fur was found which is used by the writer to represent Miss Brill's state. Therefore, the "cupboard" here is coherently related to the "cupboard" introduced in the first paragraph to indicate that all the people found in the park are similar to Miss Brill (or even her fur) in being old, odd, and coming from dark little rooms or even cupboards.

Behind the rotunda the slender trees with yellow leaves down drooping, and through them just a line of sea, and beyond the blue sky with gold-veined clouds.

Tum-tum-tum tiddle-um! tiddle-um! tum tiddley-um tum ta! blew the band. (Mansfield, 1981)

Through the identification of the location, there was a description of a part/whole relation, i.e., part of the park series is described. The "slender trees with yellow leaves down dropping through them just a line of sea, and beyond the blue sky with gold- veined clouds".

The tones produced by the band indicate a coherent shift from description to a description of what was going on through the camera eye of Miss Brill.

Two young girls in red came by and two young soldiers in blue met them, and they laughed and paired and went off arm-in-arm. Two peasant women with funny straw hats passed, gravely, leading beautiful smoke-coloured donkeys. A cold, pale nun hurried by. A beautiful woman came along and dropped her bunch of violets, and a little boy ran after to hand them to her, and she took them and threw them away as if they'd been poisoned. Dear me! Miss Brill didn't know whether to admire that or not! And now an ermine toque and a gentleman in grey met just in front of her. He was tall, stiff, dignified, and she was wearing the ermine toque she'd bought when her hair was yellow. Now everything, her hair, her face, even her eyes, was the same colour as the shabby ermine, and her hand, in its cleaned glove, lifted to dab her lips, was a tiny yellowish paw. Oh, she was so pleased to see him-delighted! She rather thought they were going to meet that afternoon. She described where she'd been-everywhere, here, there, along by the sea. The day was so charming — didn't he agree? And wouldn't he, perhaps? .. But he shook his head, lighted a cigarette, slowly breathed a great deep puff into her face, and even while she was still talking and laughing, flicked the match away and walked on. The ermine toque was alone; she smiled more brightly than ever. But even the band seemed to know what she was feeling and played more softly, played tenderly, and the drum beat, "The Brute! The Brute!" over and over. What would she do? What was going to happen now? But as Miss Brill wondered, the ermine toque turned, raised her hand as though she'd seen someone else, much nicer, just over there, and pattered away. And the band changed again and played more quickly, more gayly than ever, and the old couple on Miss Brill's seat got up and marched away, and such a funny old man with long whiskers hobbled along in time to the music and was nearly knocked over by four girls walking abreast. (Mansfield, 1981)

The opening of the seventh paragraph starts a number of predicate relations described by Miss Brill and done by people around her.

The two young girls came by and two young soldiers ... met them, they laught and paired and went off arm-in-arm. Two peasant women ... passed ... nun hurriedly, a beautiful woman came ... dropped her bunch of violets, little boy ran after to them to her, she took them away, etc. Then there is Miss Brill's identity found to give her comments about what happened by a predicate relation by wondering "whether to admire that or not!"

The sentence starting with "And now" indicates another coherent shift from giving her point of view to a description of what was happening "in front of her". A part/whole relation is indicated through "an ermine toque". This "ermine toque" symbolizes an old woman meeting an old man. This relation, also, indicates a sameness relation, i.e., an ermine toque represents the old woman just as the "fur" represents Miss Brill herself. Then an inclusion relation is indicated through "in grey" to indicate that it was an old woman with the ermine toque. The sameness relation between the toque and the fur is indicated through the comparison between the woman and the ermine toque which she ought when her hair was yellow. Furthermore, the possession relation which is between the toque and her yellow hair, her hand, her face, even her eyes, which indicate the sameness relation with that of Miss Brill and her fur in now being shappy. A contrast relation is found in the use of the words "yellow" and "yellowish" in that the first one is to show youth and the second is to refer to a hand being pale because of being old.

What is important is the leaving of the ermine toque alone. The identity of the toque being done resembles the sameness relation to that of Miss Brill's. Because of her realization of such a fact, the writer employed a predicate relation between Miss Brill's identity and the situation she was in. It was to smile more brightly than ever. Another reference to an element of the park series which is the "band" acting as if they knew what was 
going on in Miss Brill's mind in "the band seemed to know what she was feeling" and another cause/consequence relation is introduced because the band knew her feeling, it "played more, softly, played tenderly and the drum beat". Its playing resembles a reminder that she must reach the conclusion that in reality she is just like that neglecting which is living alone and part of nothing.

The questions introduced "What should she do? What was going to happen now?" are coherent enquires shedding lights upon the reality which Miss Brill did not accept by making the ermine toque do an activity relation "turn". Such a "turn" is in fact Miss Brill's turn to escape from the ugly fact that she is alone to her fancy dream that she is part of the picture since the band changed and played more quickly and gaily than ever and describing an old man as "funny ... knocked over by four girls walking abreast".

Oh, how fascinating it was! How she enjoyed it! How she loved sitting here, watching it all! It was like a play. It was exactly like a play. Who could believe the sky at the back wasn't painted? But it wasn't till a little brown dog trotted on solemn and then slowly trotted off, like a little "theatre" dog, a little dog that had been drugged, that Miss Brill discovered what it was that made it so exciting. They were all on the stage. They weren't only the audience, not only looking on; they were acting. Even she had a part and came every Sunday. No doubt somebody would have noticed if she hadn't been there; she was part of the performance after all. How strange she'd never thought of it like that before! And yet it explained why she made such a point of starting from home at just the same time each week-so as not to be late for the performance-and it also explained why she had quite a queer, shy feeling at telling her English pupils how she spent her Sunday afternoons. No wonder! Miss Brill nearly laughed out loud. She was on the stage. She thought of the old invalid gentleman to whom she read the newspaper four afternoons a week while he slept in the garden. She had got quite used to the frail head on the cotton pillow, the hollowed eyes, the open mouth and the high pinched nose. If he'd been dead she mightn't have noticed for weeks; she wouldn't have minded. But suddenly he knew he was having the paper read to him by an actress! "An actress!" The old head lifted; two points of light quivered in the old eyes. "An actress-are ye?" And Miss Brill smoothed the newspaper as though it were the manuscript of her part and said gently; "Yes, I have been an actress for a long time." (Mansfield, 1981)

The first three exclamations, which introduce what was going on in her mind, are coherently linked to the previous paragraph through describing an activity found and identified in the park frame "sitting here" as "how fantastic, she enjoyed it, how she loved" and "watching it" is coherently understood as a general activity performed by the only one character in fact she was not only watching carefully and portraiting what was going on in the general park frame but also describing her own life and sequences of activity done by her.

"It was like a play. It was exactly like a play". The word "play" is employed coherently and effectively to describe a part/whole relation. Miss Brill as well as sitting and watching every identity being part of the park series.

In fact, the comparison relation of sameness introduced by the word "play" indicates a rejection of Miss Brill's reality from being a lonely old woman to be dreaming to be part of the park life as if it is a "play" and the vividness makes it so "exciting". And what is more the park frame resembles a stage frame in "they were all on the stage "and people around in negative resemblance relation as not being audience but as actors". The predicate relation "had a part" indicates a relation in that Miss Brill possess a role in the play and the park frame possesses Miss Brill as a major element by coming "every Sunday". In addition, there is another resemblance relation indicated by the word "performance", i.e., what was going on in the park series is like a "performance" in a play and everyone performs his own role in the park/play frame.

The band had been having a rest. Now they started again. And what they played was warm, sunny, yet there was just a faint chill - a something, what was it? — not sadness-no, not sadness-a something that made you want to sing. The tune lifted, lifted, the light shone; and it seemed to Miss Brill that in another moment all of them, all the whole company, would begin singing. The young ones, the laughing ones who were moving together, they would begin, and the men's voices, very resolute and brave, would join them. And then she too, she too, and the others on the benches-they would come in with a kind of accompaniment-something low, that scarcely rose or fell, something so beautiful-moving. .. And Miss Brill's eyes filled with tears and she looked smiling at all the other members of the company. Yes, we understand, we understand, she thought-though what they understood she didn't know. (Mansfield, 1981)

A cause relation is indicated through "Miss Brill nearly laugh out loud. She was on the stage". She was happy in her dream since she was part of it and if she wasn't there something missing was to happen. She is of a value and 
of advantage because she recalled a previous activity done by her four afternoon a week by reading a newspaper to an old gentleman while he slept in the garden. She resembles herself, through a sameness relation, as an actress playing a major role in the park/play frame. Believing that she took a part in the by building a scenario in her mind with the man. She visioned that he would no longer sleep through the stories as he normally does ones he realized she was an actress and he would become engaged and excited. The old man and the newspaper are mentioned at the first time but they are coherent since both identities, "man and newspaper," are elements of the whole frame, the park.

The activity of the band "started again" linked the idea of the previous paragraph with the next one in indicating the continuity of the idea of the "play" as the band played a "warm, sunny.... Yet a faint chill...not sadness -no, not sadness" but something that made her happy to enjoy the dream away from reality visioning that everyone in the park takes part in the song and singing and describing every member and every identity in the park frame through several activities are united and start to sing. Through such an activity there is a cause/sequence relation, i.e., since the tune lifted from reality to a dream which is pictured in imaging the warm and sunny tune and therefore she cried because of happiness.

Just at that moment a boy and girl came and sat down where the old couple had been. They were beautifully dressed; they were in love. The hero and heroine, of course, just arrived from his father's yacht. And still soundlessly singing, still with that trembling smile, Miss Brill prepared to listen.

"No, not now," said the girl. "Not here, I can't."

"But why? Because of that stupid old thing at the end there?" asked the boy. "Why does she come here at all — who wants her? Why doesn't she keep her silly old mug at home?"

"It's her fu-ur which is so funny," giggled the girl. "It's exactly like a fried whiting."

"Ah, be off with you!" said the boy in an angry whisper. Then: "Tell me, ma petite chere--"

No, not here," said the girl. "Not yet." (Mansfield, 1981)

Within the peak of happiness, comes the top- down moment towards reality. This is so because of another but young couple shared her bench. So the words "at that moment "refers to the idea found in the previous paragraph, the moment of happiness.

The new couples introduced through a cause/sequence relation by indicating "they were beautifully dressed"; therefore, "they were in love". She resembles them as "a hero and heroine" through a resemblance relation. The phrase "still soundlessly singing", links those couple with the previous portrait of the whole elements of the park series with which all engaged in singing with the band.

The sentence, "Still with that trembling smile, Miss Brill prepared to listen", contains an activity previously done by her which links with what was previously done and what was going to be done.

The fragments, "No, not now ... Not here, I can't. But why? Because of that stupid old thing at the end there?" are coherently linked to the reality (to the situation) more than to the imaginary world she dreamed of in the previous paragraph." That stupid old thing "represents her reality. Furthermore, the questions "why does she come here at all - who wants her?" is coherently linked to the delightful answers provided by her that she has an important role in the park frame but through a contrast relation indicating her uselessness being stupid, old, and not only that but also "her silly old mug" which resembles her and the fur which was so funny is indicated by the giggling done by the girl and sameness relation "like a fired whiting".

On her way home she usually bought a slice of honey-cake at the baker's. It was her Sunday treat. Sometimes there was an almond in her slice, sometimes not. It made a great difference. If there was an almond it was like carrying home a tiny present-a surprise - something that might very well not have been there. She hurried on the almond Sundays and struck the match for the kettle in quite a dashing way. (Mansfield, 1981)

In the last but one paragraph, the adverb "usually" indicates a series of activities she used to do every Sunday after spending the afternoon in the park as: "going home, bought a slice of honey-cake at the baker's, carrying home a tiny present, hurried, stuck the match" and possessor/possessed relations as:" the baker's, her Sunday treat and her slice". A resemblance relation is also indicated through "it was like carrying home a tiny present" and such a present is like a "surprise".

But to-day she passed the baker's by, climbed the stairs, went into the little dark room-her room like a cupboard-and sat down on the red eiderdown. She sat there for a long time. The box that the fur came out of was on the bed. She unclasped the necklet quickly; quickly, without looking, laid it inside. But 
when she put the lid on she thought she heard something crying. (Mansfield, 1981)

The phrase "But today" indicates a contrast relation from an activity she used to do to the realization of reality to the "sadness" she usually kept herself away. "She bought a slice of honey cake at the baker's" and "she passed the baker's by".

Predicate relations are indicated through several activities done by the same identity Miss Brill: climbed the stairs, went into the little dark room, sat down on the red eiderdown, sat there, unclasped the necklet, laid it inside, put the lid on, thought and something crying".

The little dark room and the cupboard is coherently understood and related to the first paragraph and to the fifth paragraph. "The box" is the same as that mentioned in the first paragraph. Finally the activity "crying" carries a sense of resemblance to Miss Brill's estate in being "crying" also since the fur represents a symbol to Miss Brill.

\subsection{Global Coherence}

Global coherence is clear through:

Location. The whole story's place of happening starts with the "little dark room" where Miss Brill is and where "the box" of the "fur" is in and ends in the same place.

Another location where the story scene lies in the park frame through which the happening of the story lies and where Miss Brill was in order to proceed the story. The coherence is clear through words that are attached to the park place as: the park, seat, bench, beach, the sky, trees, leaves, etc.

The whole story keeps happening in the past by the past tense employed by the writer and by the use of adverbs indicating the past happening of some activities as "Last Sunday", "four weeks before", etc.

Activity sequences. The whole story is globally coherent through repeating the activity "sitting" performed by Miss Brill and the others "sitting" in the park and employing it to deepen the idea that she herself was "sitting" on other's lives through listening to their conversations.

The story is also coherently linked through the "coming" and "going" of the people in the park frame through the whole story.

Some Nouns and Noun Phrases. Some nouns are coherently employed to enrich the theme as the word "fur" through the resemblance relation between it and Miss Brill. The word "box" in the first paragraph is also repeated in the last one. The repetition of the noun phrase" old people" to refer to Miss Brill as well as to the people whom she was sitting on their lives.

\section{Conclusion}

It is concluded that Katherine Mansfield was keen enough to make her story coherent whether through local coherence or global coherence. This is true, according to the model followed, locally through employing the consequences of the story through the relations as: part/whole relation, comparison relation of sameness/resemblance as well as contrast, possessor/possessed relation, set/subset/element relation and cause consequence relation.

Globally, the story is coherent through the unity of time, place, activity sequences, and the repetition of some nouns and noun phrases through the whole story.

\section{References}

Al-Sahlany, Q. A. (2013). Local and Global Coherence in Translation. Journal of Human Sciences-College of Education for Human Sciences, 14.

Beaugrande, R.-A. D. (1991). Linguistic Theory: The Discourse of Fundamental Works. Routledge.

Blommaert, J. (2005). Discourse: A Critical Introduction (Key Topics in Sociolinguistics). Cambridge University Press. http://dx.doi.org/10.1017/CBO9780511610295

Cook, G. (1989). Discourse. Oxford: OUP.

Dijk, T. A. V. (1980). Text and Context: Explorations in the Semantics and Pragmatics of Discourse. Longman Group United Kingdom.

Mansfield, K. (1981). Miss Brill. Retrieved March 3, 2013, from http://www.eastoftheweb.com/short-stories/UBooks/MissBril.shtml

Renkema, J. (2009). Discourse, of course: An overview of research in discourse studies. John Benjamins Publishing. http://dx.doi.org/10.1075/z.148 
Winter, E. O. (1971). Connection in Science Material: A proposition about the Semantics of Clause Relations. Center for Information on Language Teaching papers and Reports, 7.

Winter, E. O. (1977). A clause-relational approach to English texts: A study of some predictive lexical items in written discourse. Instructional Science, 6(1), 1-92. http://dx.doi.org/10.1007/BF00125597

\section{Copyrights}

Copyright for this article is retained by the author(s), with first publication rights granted to the journal.

This is an open-access article distributed under the terms and conditions of the Creative Commons Attribution license (http://creativecommons.org/licenses/by/3.0/). 